\section{Anaesthetic issues related to incidental unruptured intracranial aneurysm}

\section{Prakash K. Dubey, Om P. Sanjeev}

Sir,

The fastest growing group of patients with aneurysms consist of those patients with previously ruptured and treated cerebral aneurysms. These patients are at high risk for harbouring unruptured asymptomatic intracranial aneurysms. Sixteen percent incidence of new aneurysm formation, both at the previous and a new site, was shown in 610 patients followed over 15 years after surgical clipping of a ruptured aneurysm. ${ }^{[1]}$ This suggests that development of intracranial aneurysm is not a once in a lifetime event but rather a continuous process. Familiarity with the natural history and the risks associated with an intra cerebral aneurysm will help in management if such a patient turns up for an incidental surgery.

Presented here is the anaesthetic management of a patient posted for excision of osteomyelitic temporoparietal bone and wound debridement under general anaesthesia with an incidentally diagnosed aneurysm at the origin of right posterior inferior cerebellar artery.

A 65-year-old female, weighing $62 \mathrm{~kg}$, reported to the outpatient department with a complaint of headache, occasional fever and pus discharge from the right side of skull for the last 2 years. She had undergone some neurosurgery about 4 years back but had no details of the procedure. Her physical examination was unremarkable and the routine haematological investigations were within normal limits. Her hypertension was controlled with amlodipine $5 \mathrm{mg}$ daily. A plain X-ray of the skull showed evidence of

Department of Anaesthesia, Indira Gandhi Institute of Medical Sciences, Patna, Bihar, India

Address for correspondence:

Dr. Prakash K. Dubey, E 3/4, Indira Gandhi Institute of Medical Sciences, Patna - 800 014, Bihar, India. E-mail: pkdubey@hotmail.com 
osteomyelitis and two metallic foreign bodies suggestive of aneurysm clips. A computed tomography (CT) scan confirmed the presence of metallic clips and also revealed irregular temporoparietal bone with surrounding inflammatory changes consistent with osteomyelitis. A CT angiogram of the brain followed to assess the status of the clipped aneurysm and to screen for development of any new aneurysm. It showed metallic clip in the region of distal M1/ proximal M2 segment of right middle cerebral artery. It showed a good flow within the peripheral middle cerebral artery distal to M2 segment. The CT angiogram also revealed the presence of a $4 \mathrm{~mm} \times 4 \mathrm{~mm}$ size aneurysm with a $4 \mathrm{~mm}$ wide neck arising at the origin of right posterior inferior cerebellar artery [Figure 1].

Anaesthesia was induced with fentanyl $200 \mu \mathrm{gm}$ and propofol $100 \mathrm{mg}$ after institution of electrocardiograph (ECG), pulse oximeter and left radial artery cannulation under local anaesthesia. Tracheal intubation was facilitated with vecuronium $6 \mathrm{mg}$ and anaesthesia was maintained with $1 \%$ sevoflurane and $60 \%$ nitrous oxide in oxygen along with intermittent positive pressure ventilation. Excision of osteomyelitic temporoparietal bone and wound debridement was performed. A $0.5 \mathrm{~cm} \times 0.5 \mathrm{~cm}$ size piece of bone wax was recovered from the extradural space. It is possible this led to the osteomyelitis of the bone flap of the previous craniotomy. The surgical procedure took about 90 minutes and after another bolus of fentanyl $50 \mu \mathrm{gm}$, neuromuscular blockade was reversed with neostigmine and glycopyrrolate and trachea was extubated. During the laryngoscopy and intubation the maximum mean arterial pressure recorded was $86 \mathrm{~mm}$ of $\mathrm{Hg}$ and at the termination of anaesthesia the maximum recorded was $95 \mathrm{~mm}$ of $\mathrm{Hg}$. The patient remained haemodynamically stable intraoperatively and the end tidal carbon-di-oxide was maintained between $33 \mathrm{~mm}$ of $\mathrm{Hg}$ and $36 \mathrm{~mm}$ of $\mathrm{Hg}$.

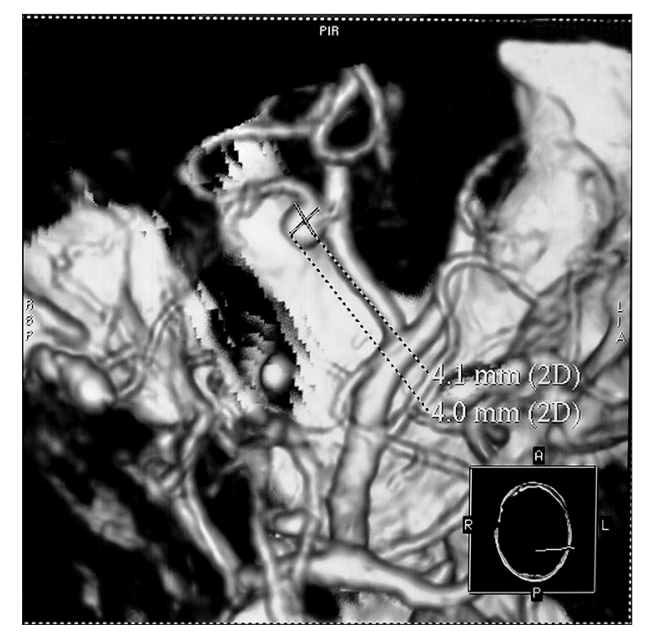

Figure 1: Computed tomographic angiogram of the vertebrobasilar system showing the aneurysm of the right posterior inferior cerebellar artery
Anaesthetic management of incidental surgery in a patient with unruptured intracranial aneurysm is a challenge for anaesthesiologist. Regardless of the surgical procedure, the main aim is to maintain stable transmural pressure in the aneurysm to prevent rupture that may be catastrophic.

Laryngoscopy and tracheal intubation produce haemodynamic changes that can increase transmural pressure of aneurysm predisposing to its rupture. ${ }^{[2]}$ Proper attention should be paid to other factors that may alter the blood pressure or intracranial pressure intraoperatively like adequate analgesia, sedation, muscle relaxation, oxygenation, volume status and avoidance of hypo or hypercarbia. During tracheal extubation and in the immediate postoperative period, all efforts should be made to avoid hypercarbia, hypertension, shivering, coughing and straining. Dangerous hypertension that can result from a preexisting hypertensive disease, pain, carbon-di-oxide retention, a blocked urinary catheter and emergence hypertension commonly seen in neurosurgical patients should be avoided.

A neurological examination in the immediate postoperative period is essential. Failure to regain consciousness or development of a new neurological deficit should lead to the suspicion of a rupture of aneurysm. Other causes of an altered sensorium like residual effects of anaesthetics, hypercarbia, hypoxia and hyponatremia should be excluded.

In this patient, an intraarterial catheter was inserted for optimum management of blood pressurefluctuations. The anaesthetic agents used proved to be adequate for this purpose. Proper control of blood pressure rather than use of any particular agent is important. Intravenous esmolol or labetalol are recommended for control of blood pressure in these situations.

Multiple aneurysms may be present in approximately $15-20 \%$ of all aneurysm patients. ${ }^{[3]}$ Patients with a history of subarachnoid haemorrhage may be at risk for new aneurysm formation-both de novo (at a new site) and regrowth (adjacent to the clip or coil from previous treatment).$^{[1]}$ In this patient, a $4 \mathrm{~mm}$ size new aneurysm was found in the right posterior inferior cerebellar artery after previous clipping of right middle cerebral artery aneurysm. It has been found that for an aneurysm less than $7 \mathrm{~mm}$ the risk of rupture is more $(2.5 \%)$ if involving the posterior circulation than the anterior circulation $(0 \%){ }^{[4]}$

CT-angiography is a relatively non-invasive and widely available screening technique for these patients. ${ }^{[1]}$ A patient who has undergone clipping of an aneurysm shall be subjected to screening to evaluate the site of clipping and to rule out another aneurysm grown there or elsewhere. 


\section{REFERENCES}

1. Wermer MJ, van der Schaaf IC, Velthuis BK, Algra A, Buskens E, Rinkel GJ. ASTRA Study Group. Follow-up screening after subarachnoid haemorrhage: Frequency and determinants of new aneurysms and enlargement of existing aneurysms. Brain 2005;128:2421-9.

2. Priebe HJ. Aneurysmal subarachnoid haemorrhage and the anaesthetist. Br J Anaesth 2007;99:102-18.

3. Britz GW, Winn HR. The natural history of unruptured saccular cerebral aneurysm. In: Win HR, editor. Neurological surgery. $5^{\text {th }}$ ed. Philadelphia: Saunders; 2004. p. 1781-92.

4. Wiebers DO, Whisnant JP, Huston J $3^{\text {rd }}$, Meissner I, Brown RD Jr, Piepgras DG, et al. International Study of Unruptured Intracranial Aneurysms Investigators. Unruptured intracranial aneurysms: Natural history, clinical outcome, and risks of surgical and endovascular treatment. Lancet 2003;362:103-10.

\begin{tabular}{|l|l|}
\hline \multicolumn{2}{|c|}{ Access this article online } \\
\hline Quick Response Code: & Website: \\
\hline & www.jnaccjournal.org \\
\cline { 2 - 2 } & \\
\hline
\end{tabular}

